\section{ESTUDO DE CASO: O DESIGN DE JOIAS DE UM FIGURINO DE DANÇA ORIENTAL}

\section{CASE STUDY: THE DESIGN OF JEWELRY FOR AN ORIENTAL DANCE COSTUMES}

\author{
Stephany de Souza Silva ${ }^{1}$ \\ Claudia Regina Batista², Dra. \\ (1) Universidade Federal de Santa Catarina \\ e-mail: pi.stephany@gmail.com \\ (2) Universidade Federal de Santa Catarina \\ e-mail: claudia.batista@ufsc.br
}

Palavras-chave em português Design de joias, figurino, ergonomia.

Este artigo relata o processo de design das joias que compõem o figurino de um espetáculo de dança oriental. A Ergonomia possui fundamental importância neste projeto, pois buscou-se propiciar o conforto e a segurança à usuária e, também, a facilidade e praticidade na interação com o produto. O processo de design foi guiado pela metodologia de design de joias proposta por Batista $(2012,2017)$ e foram realizados testes ergonômicos e de usabilidade com a usuária, conforme previsto na metodologia.

Key-words in English Jewelry design, costumes, ergonomics.

This paper describes the design process for jewelry that make up the costume of an oriental dance show. Ergonomics has fundamental importance in this project, because it was sought to provide comfort and security to the user and ease and practicality in interacting with the product. The design process was guided by the jewelry design methodology proposed by Batista (2012, 2017); ergonomic and usability tests were also performed with the user, as foreseen in the methodology.

\section{Introdução}

Este projeto foi realizado a partir da demanda do espetáculo de dança oriental "Minha Arte". No figurino, o traje já havia sido idealizado, contudo faltavam os acessórios/adereços que caracterizam e ornamentam o traje.

Um dos primeiros aspectos que se deve ter em mente é que durante a execução dos movimentos da coreografia, o figurino (traje e adereços) não deve ser incômodo, desconfortável, nem comprometer o desempenho da bailarina. Há relatos de bailarinos sobre alguns problemas que ocorrem durante o uso do figurino no espetáculo; quando o traje e adereços não são desenvolvidos apropriadamente eles podem causar pequenas lesões na pele (tais como bolhas, fissuras) devido a pressão ou tração sobre o corpo.
Realização:

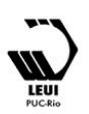




\section{$16^{\circ}$ \\ ERGODESIGN USIHC CINAHPA}

Diante deste contexto, tornou-se possível elaborar a seguinte questão de pesquisa: Quais são os requisitos para desenvolver um conjunto de joias/semijoias anatômicas, confortáveis e seguras que permitam à bailarina executar os movimentos corporais necessários a coreografia num espetáculo de dança?

O objetivo geral deste estudo foi desenvolver o projeto das joias que compõem o figurino para o espetáculo de dança "Minha arte", priorizando o conforto da bailarina, além de adequar-se aos requisitos da produção artística, como a coerência com o tema da produção e o traje do figurino.

Os objetivos específicos foram: levantar os dados antropométricos da bailarina; adequar a configuração e as dimensões das peças em conformidade com os dados antropométricos; testar as peças visando identificar se elas são confortáveis, seguras e se permitem à bailarina executar livremente a coreografia.

\section{Espetáculo de Dança}

Um espetáculo de dança é uma apresentação pública destinada a entreter. É a representação de um enredo por meio de elementos distintos, tais como figurino, cenário e iluminação, que são desenvolvidos em conjunto para expressarem o conceito substancial do tema. Esses elementos contribuem com cores e formas para traduzir o enredo. (CASTRO; COSTA, 2010, p. 80)

No espetáculo de dança, além dos elementos comuns a outros espetáculos cênicos, tais como a ambientação e contextualização do tema, a coreografia também faz parte desses meios de representar o enredo.

\subsection{A Dança Oriental}

A dança oriental, Raks el Sharq em árabe, popularmente conhecida no Brasil como dança do ventre, surgiu a partir da religião e não se pode afirmar com precisão o local de sua origem.

Algumas das antigas civilizações do Oriente Médio utilizavam a dança como uma forma especial e direta de cultuar seus deuses. Nos antigos templos, a dança era uma condição propícia ao transe, e que poderia $16^{\circ}$ Ergodesign - Congresso Internacional de Ergonomia e Usabilidade de Interfaces Humano Tecnológica: Produto, Informações Ambientes Construídos e Transporte

$16^{\circ}$ USIHC - Congresso Internacional de Ergonomia e Usabilidade de Interfaces Humano Computador

CINAHPA | 2017 - Congresso Internacional de Ambientes Hipermídia para Aprendizagem. levar a pessoa a um estado de comunicação direta com o mundo espiritual. (BENCARDINI, 2002, p. 25)

Ao longo dos séculos, as influências para formação da dança oriental como é conhecida hoje veio dos sumérios, mesopotâmios, fenício, persas, egípcios e indianos. (BENCARDINI, 2002)

A dança oriental chegou ao Brasil com a imigração de árabes que iniciou em cerca de 1880; estes eram árabes cristãos, vindos da Síria e do Líbano principalmente, e que se dirigiram para o sudeste do país. Na metade do século seguinte, árabes muçulmanos começaram a morar no Brasil. E nas décadas seguintes, uma diferente leva de libaneses fugida da guerra também fez o mesmo caminho.

(BENCARDINI, 2002)

$\mathrm{Na}$ apropriação da dança do ventre pelo contexto brasileiro, é priorizada sua função estética. O aparecimento da dança árabe no Brasil é relativamente recente, sendo introduzida no modo mais sólido no início dos anos 70 , por meio de apresentações realizadas em restaurantes árabes [...] Nessa época, o público era em sua maioria pessoas da colônia árabe. (REIS, 2013, p. 34)

\subsection{O Figurino para a Dança Oriental}

Segundo Castro; Costa (2010, p. 80):

O figurino pode ser entendido como o traje cênico, ou mesmo o conjunto da indumentária e adereços, criado ou produzido pelo figurinista e utilizado pelo artista para compor seu personagem em determinada forma de expressão artística, como o teatro, cinema, televisão, ópera, dança e outros meios de manifestação artística.

O figurino da dança oriental sofreu diferentes mudanças ao longo dos anos. No início, as dançarinas usavam roupas de seu cotidiano e, posteriormente, as bailarinas passaram a usar vestimentas especiais para a dança.

Cenci (2001) relata um fato curioso: as dançarinas convertiam o dinheiro ganho com as apresentações em joias, que usavam habitualmente. Quanto mais adornada estivesse a dançarina, maior era o status da artista. 


\section{$16^{\circ}$ \\ ERGODESIGN USIHC CINAHPA}

$16^{\circ}$ Ergodesign - Congresso Internacional de Ergonomia e Usabilidade de Interfaces Humano Tecnológica: Produto, Informações Ambientes Construídos e Transporte

$16^{\circ}$ USIHC - Congresso Internacional de Ergonomia e Usabilidade de Interfaces Humano Computador

CINAHPA | 2017 - Congresso Internacional de Ambientes Hipermídia para Aprendizagem.

\begin{abstract}
A década de 1920 trouxe a influência ocidental para os figurinos, mas ainda sim se adaptando aos costumes e tabus dos países árabes. A proibição de expor os umbigos fez com que as bailarinas usassem joias para cobrir o umbigo, ou roupas com malhas transparentes, com gemas bordadas no local do umbigo. (CENCI, 2001, p. 47)
\end{abstract}

A figura 1 mostra a evolução do figurino da dança oriental, desde a chamada "era de ouro" até a variação ATS - American Tribal Style.

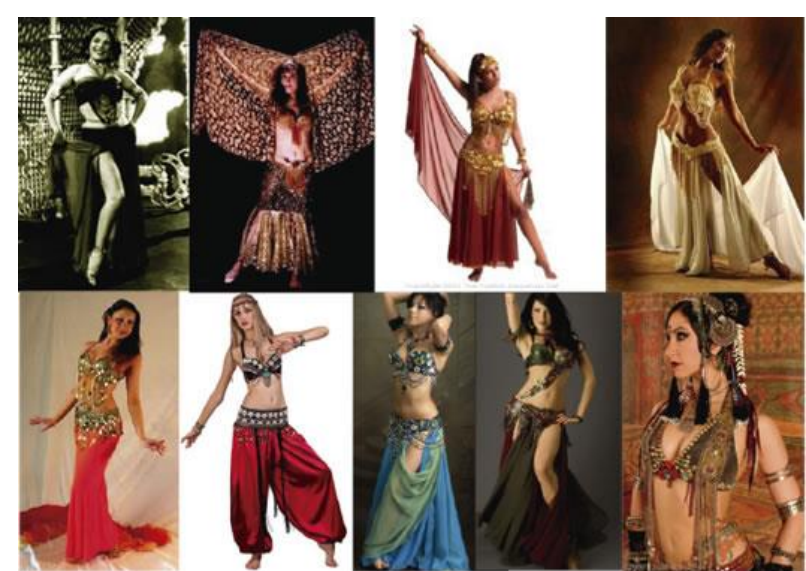

Figura 1 - A evolução do figurino da dança oriental Fonte: Silva (2016, p. 48)

Durante a composição do figurino, o uso de adereços (ou até mesmo a falta deles) ajuda a transparecer a ideia principal do espetáculo. Eles completam o traje, possibilitam maior diferenciação e acrescentam individualidade ao figurino do bailarino.

Assim como nas apresentações de outros estilos rítmicos, o figurino (traje e adereços) para dança oriental deve permitir a movimentação da bailarina sem que um recurso de apoio à sua expressão prejudique seu desempenho.

A escolha dos adereços na dança oriental não deve ser pautada apenas nos fatores estéticos. La Regina (1998, p. 52) comenta sobre possíveis incidentes e alerta para que haja harmonização entre o tamanho da bailarina e os brincos por ela usados. Além disso, se os brincos e as pulseiras não são bem presos podem cair. Outro cuidado que se deve ter com as joias durante a dança é o fato que elas podem enroscar em cabelos e véus.

\section{0 design das joias para o figurino do espetáculo de dança "Minha Arte"}

\subsection{A metodologia do projeto}

A metodologia adotada para o design de joias foi proposta por Batista $(2012 ; 2017)$, as principais etapas que compõem esse método estão apresentadas na figura 2 .

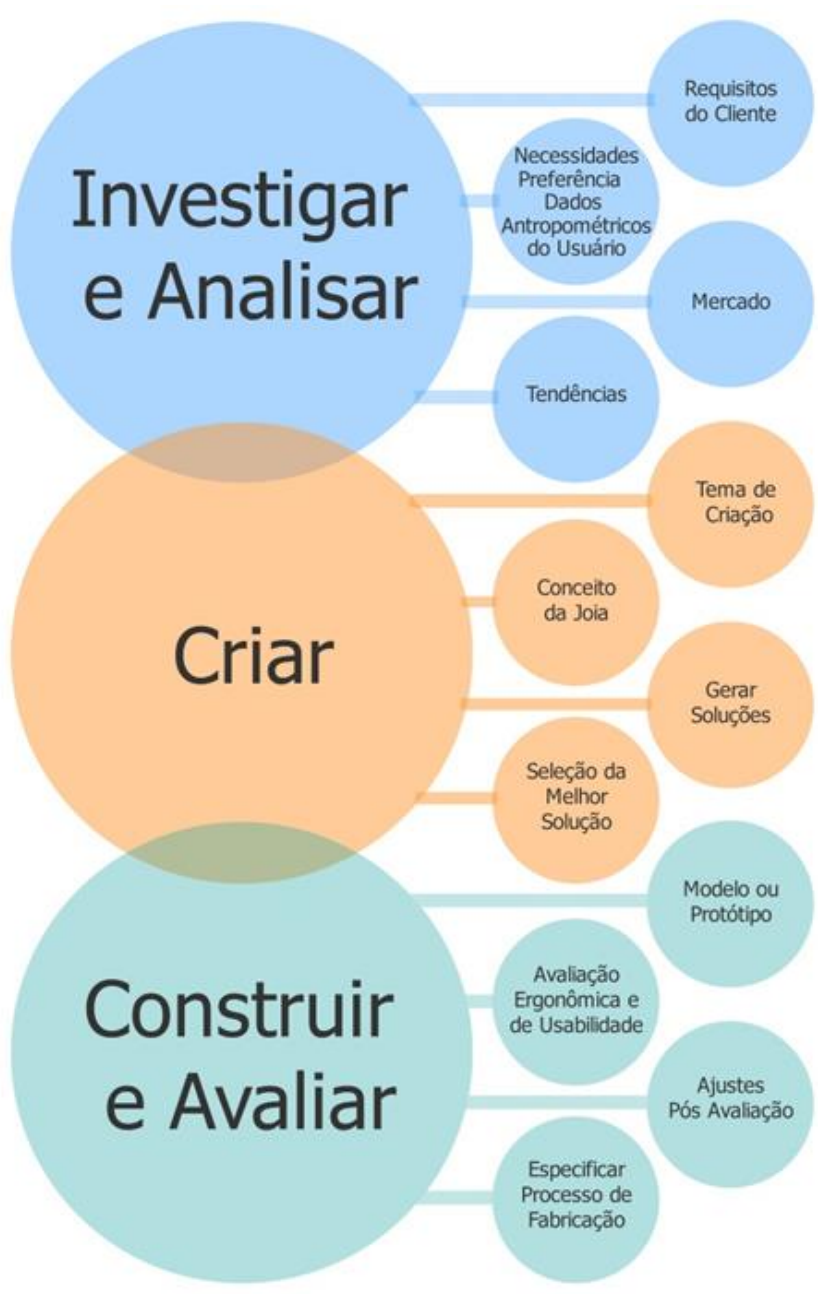

Figura 2- Proposta metodológica para Design de joias Fonte: Batista (2012; 2017).

Na sequência são apresentados os resultados obtidos nas etapas do processo do design de joias.

\subsubsection{A etapa Investigar e Analisar}

A investigação (buscar dados) e a análise dos dados coletados são o ponto de partida no design de joias. 


\section{$16^{\circ}$ \\ ERGODESIGN USIHC CINAHPA}

$16^{\circ}$ Ergodesign - Congresso Internacional de Ergonomia e Usabilidade de Interfaces Humano Tecnológica: Produto, Informações Ambientes Construídos e Transporte

$16^{\circ}$ USIHC - Congresso Internacional de Ergonomia e Usabilidade de Interfaces Humano Computador

CINAHPA | 2017 - Congresso Internacional de Ambientes Hipermídia para Aprendizagem.

De acordo com Batista (2004, p. 4):

\begin{abstract}
Para propiciar um ajuste anatômico e definir as dimensões de uma joia, torna-se necessário realizar o levantamento das dimensões estruturais (estáticas) do futuro usuário em tabelas antropométricas.
\end{abstract}

O quadro 1 relaciona as partes do corpo envolvidas e os tipos de peças da joalheria:

Quadro 1 - Medidas do corpo humano utilizadas no design de joias

b) Necessidades, Preferência e Dados Antropométricos

É imprescindível que o designer investigue e analise o perfil do usuário para identificar as necessidades, as preferências, a experiência do usuário e os dados antropométricos para conceber produtos anatômicos e confortáveis. Também é relevante identificar dados do usuário tais como a faixa etária, o gênero (feminino, masculino), o nível sócio-econômico-cultural e o estilo de vida (por exemplo: esportivo, urbano, rural, clássico, naturalista, executivo, despojado, entre outros).

Para identificar os dados referentes ao perfil do usuário foram realizadas: entrevistas com a bailarina Lana Shazadi, em 11 de maio de 2016; coleta dos dados antropométricos e aplicação de questionário.

O espetáculo "Minha arte" caracteriza-se como dança solo, portanto há demanda de figurino para uma bailarina. Dessa forma, partiu-se para a coleta dos dados antropométricos da bailarina que fará uso do conjunto de joias.

No dia 13 de maio de 2016 foi realizada a coleta dos dados antropométricos onde foram utilizadas uma fita métrica e aneleira (figura 3 ).

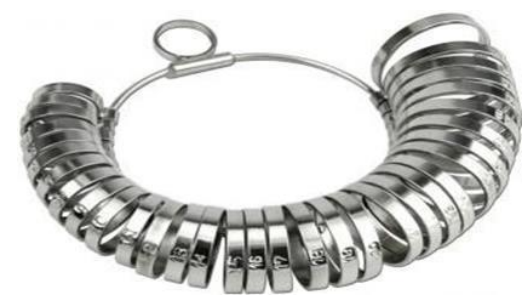

Figura 3 - Aneleira.

Fonte: Rei da Bijuteria (2016).

\begin{tabular}{|l|l|}
\hline \multicolumn{1}{|c|}{ Joia } & Parte do corpo específica e sua medida \\
\hline Anel & $\begin{array}{l}\text { Diâmetro e comprimento dos dedos das } \\
\text { mãos }\end{array}$ \\
\hline Pulseira & Perímetro do pulso \\
\hline Bracelete & Perímetro do antebraço \\
\hline $\begin{array}{l}\text { Gargantilha } \\
\text { Colar }\end{array}$ & Perímetro do pescoço \\
\hline $\begin{array}{l}\text { Brinco rígido, } \\
\text { com pendentes } \\
\text { e argolas }\end{array}$ & $\begin{array}{l}\text { Distância do centro do lóbulo da orelha } \\
\text { lóbulo até o ombro }\end{array}$ \\
\hline Tiara & Perímetro da cabeça \\
\hline Tornozeleira & Perímetro do tornozelo \\
\hline
\end{tabular}

Fonte: Batista (2004, p. 4) (adaptado de Frisoni, 2003).

No design de joias, conforme o quadro 1, torna-se necessário a obtenção de perímetros de algumas partes do corpo humano. Tais perímetros são medidas que determinam os valores de circunferência de um segmento corporal perpendicular ao eixo longitudinal do mesmo segmento.

A figura 4 demonstra as medidas referentes aos diâmetros dos dedos da bailarina, obtidas através da aneleira e elas são necessárias para a produção de anéis. Na figura 5 são apresentadas as seguintes medidas: circunferência da fronte; distância entre lóbulo da orelha ao ombro; circunferência do pescoço; circunferência da cintura; circunferência do quadril; circunferência do punho; distância entre dedo anelar e punho; circunferência do tornozelo.
Realização:

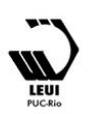



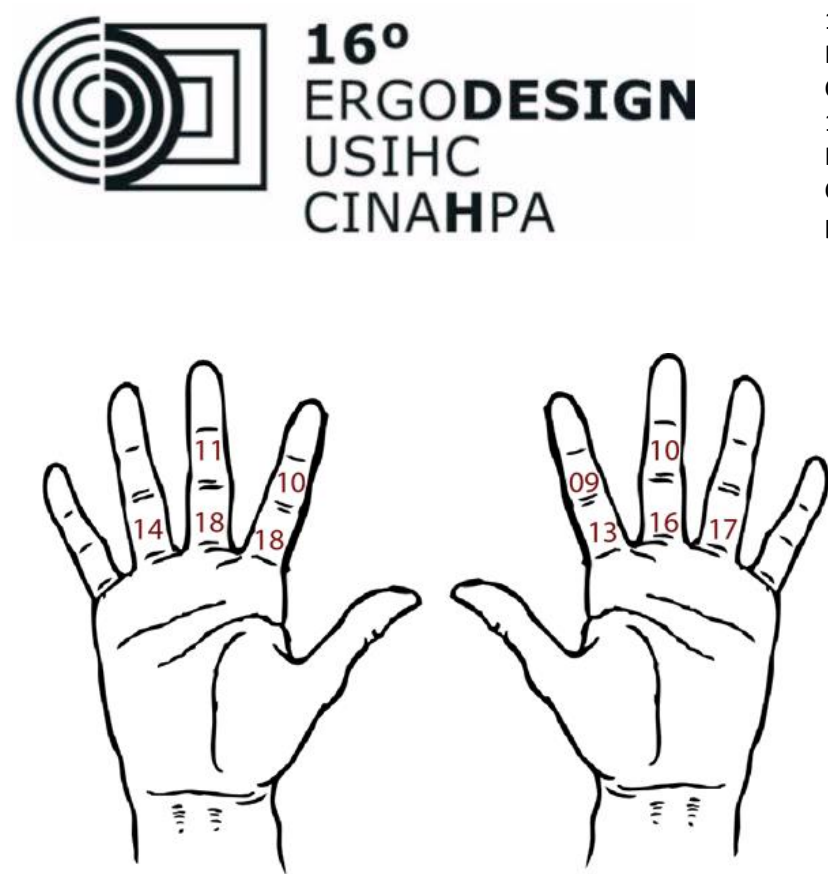

Figura 4 - Aneleiras da bailarina (diâmetro dos anéis). Fonte: Silva (2016, p. 48)

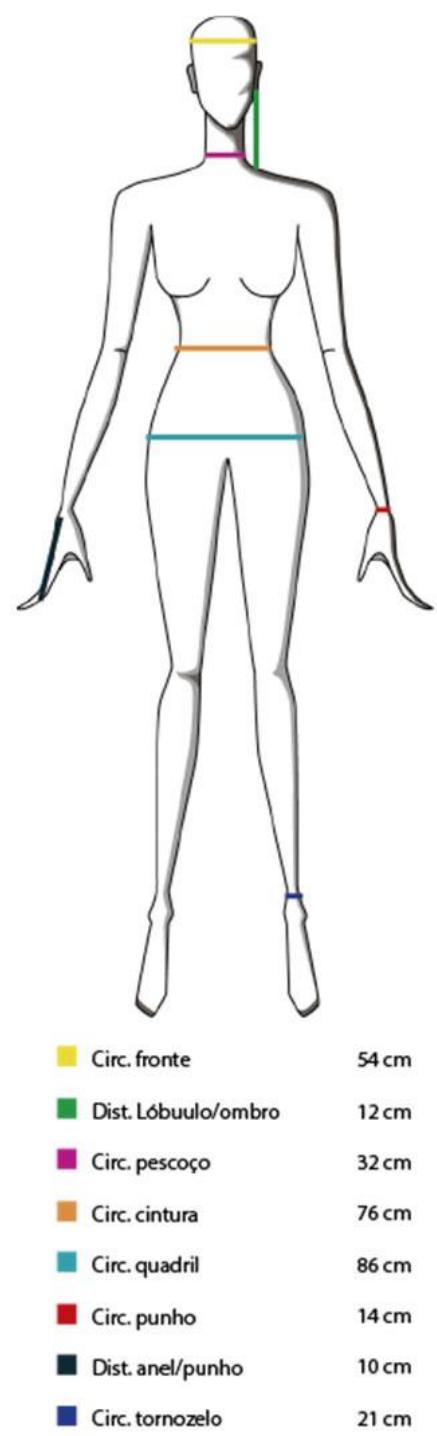

Figura 5 - Medidas das circunferências da bailarina Fonte: Silva (2016, p. 48) $16^{\circ}$ Ergodesign - Congresso Internacional de Ergonomia e Usabilidade de Interfaces Humano Tecnológica: Produto, Informações Ambientes Construídos e Transporte

$16^{\circ}$ USIHC - Congresso Internacional de Ergonomia e Usabilidade de Interfaces Humano Computador

CINAHPA | 2017 - Congresso Internacional de Ambientes Hipermídia para Aprendizagem.
c) Mercado

Uma pesquisa de mercado propicia compreender os potenciais clientes, conhecer os concorrentes e verificar a existência de um público disposto a adquirir o novo produto. Também é importante conhecer os produtos similares; para tanto pode-se fazer um Benchmarking para identificar os melhores atributos nesta categoria de produtos para alcançar um nível de superioridade ou vantagem competitiva.

Nesse estudo, o Benchmarking teve como objetivo verificar quais são as joias mais utilizadas por bailarinas durante apresentações de dança oriental. Foram selecionadas cinco bailarinas profissionais e listados 10 modelos de joias para verificar quais são as peças mais presentes nos figurinos.

Através do gráfico 1, pode-se visualizar o resultado do Benchmarking referente as joias preferidas pelas bailarinas profissionais.

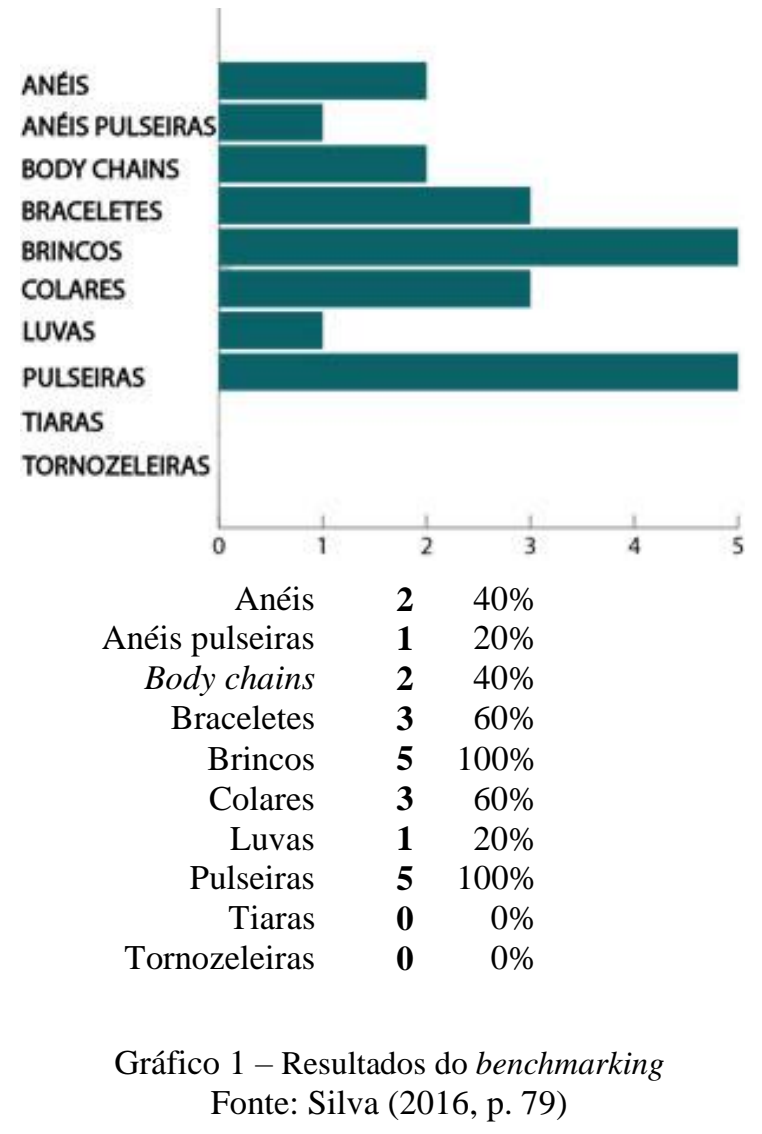




\section{$16^{\circ}$ \\ ERGODESIGN USIHC CINAHPA}

Os brincos são utilizados em 100\% dos figurinos analisados, assim como as pulseiras. Outro acessório utilizado pela maioria das bailarinas são os braceletes e os colares (60\%). Outros adereços como anéis e body chains são usados em $40 \%$ dos figurinos. Já os anéis pulseiras e as luvas são usados com menos frequência, apenas em $20 \%$ dos casos.

\section{d) Tendências}

No questionário aplicado aos participantes, havia uma questão sobre a influência das tendências da moda na escolha dos adereços. Nenhuma resposta apontou considerar esse fator durante a escolha do adereço. Somando esse dado à análise dos adereços ao longo da história da prática da dança oriental, pode-se observar que as tendências vigentes da moda não exercem grande influência na modelagem das peças. As mudanças sobre estética do figurino (traje e adereços) é feita de acordo com o estilo da dança praticada. Sendo assim, as tendências de moda (dos Bueraus que prospectam sobre o comportamento dos consumidores) não se aplicam especificamente para neste projeto.

\section{e) Requisitos de Projeto}

Após a análise dos dados coletados foram estabelecidos os requisitos para o desenvolvimento das joias para o figurino do espetáculo "Minha Arte" (ver quadro 2).

Quadro 2 - Requisitos de projeto

\begin{tabular}{|l|c|c|}
\multicolumn{1}{|c|}{ Requisito } & Obrigatório & Desejável \\
\hline Adequação antropométrica & $\mathbf{X}$ & \\
\hline Coerência com a cultura árabe & & $\mathbf{X}$ \\
\hline Coerência com conceitos de projeto & $\mathbf{X}$ & \\
\hline Coerência com figurino & & $\mathbf{X}$ \\
\hline $\begin{array}{l}\text { Coerência com tema do } \\
\text { espetáculo }\end{array}$ & $\mathbf{X}$ & \\
\hline Leve & $\mathbf{X}$ & \\
\hline Não prende/enrosca & $\mathbf{X}$ & \\
\hline Não solta/desprende & $\mathbf{X}$ & \\
\hline Resistente & $\mathbf{X}$ & \\
\hline
\end{tabular}

Fonte: Silva (2016, p. 82) $16^{\circ}$ Ergodesign - Congresso Internacional de Ergonomia e Usabilidade de Interfaces Humano Tecnológica: Produto, Informações Ambientes Construídos e Transporte

$16^{\circ}$ USIHC - Congresso Internacional de Ergonomia e Usabilidade de Interfaces Humano Computador

CINAHPA | 2017 - Congresso Internacional de Ambientes Hipermídia para Aprendizagem.

\subsubsection{A etapa Criar}

a) Tema de Criação

O tema de criação/inspiração para o conjunto de joias foi escolhido após avaliar elementos pertencentes à cultura árabe e os diferentes povos que a compõe. Como tema de criação foi selecionada a serpente, figura presente dentro da dança oriental como elemento cênico. Segundo Penna (1993, p. 134) "a serpente possui representações culturais desde os mais antigos registros da humanidade".

Ao contrário da visão Ocidental, na qual a serpente é vista como nociva, segundo Penna (1993, p. 135), na cultura árabe ela está relacionada à cura e saúde. De acordo com Guénon (2016, p. 136), as palavras "serpente" e "vida" possuem a mesma raiz etimológica na língua árabe. Os termos $a l$ hayyah (serpente) e al-hayat (vida) partilham o radical hayi. Segundo Penna (1993), essa raiz em comum das palavras significa "aquele que vivifica". A relação da serpente com o projeto ocorre pela importância desse símbolo para cultura dessa região.

Com base nisso, foi definido como tema " $\mathrm{Al}$ Hayyah", na qual a serpente e seus conceitos dentro da cultura oriental servem como base para o desenvolvimento do projeto, como apresentado na figura 6 .

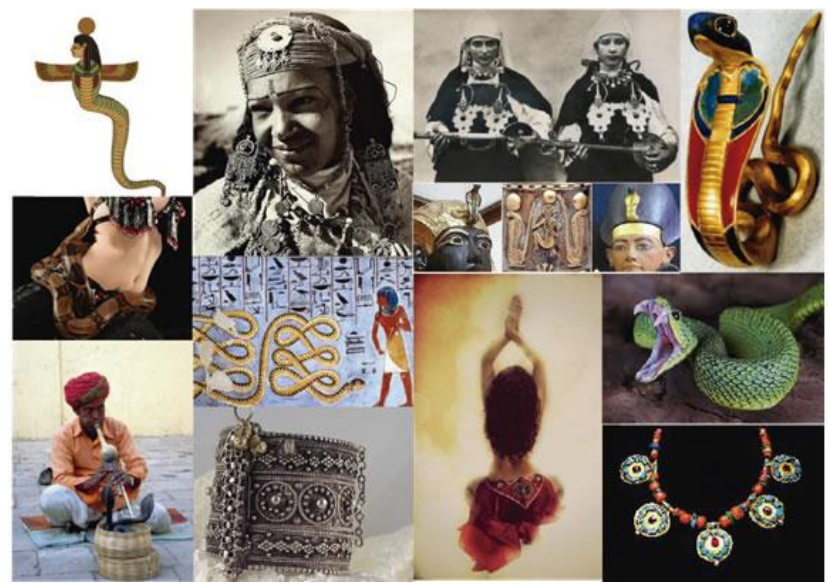

Figura 6 - Painel do tema de criação: serpente Fonte: Silva (2016, p. 83)
Realização:
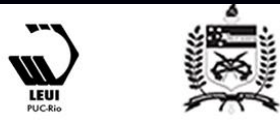
$16^{\circ}$ USIHC - Congresso Internacional de Ergonomia e Usabilidade de Interfaces Humano Computador

CINAHPA | 2017 - Congresso Internacional de Ambientes Hipermídia para Aprendizagem.

\section{b) O Conceito do Conjunto de Joias}

Para desenvolver o conjunto de joias foram definidos 5 conceitos:

- Feminino: a feminilidade acrescenta o esmero e a sofisticação necessários para representar a delicadeza de uma arte ligada ao empoderamento feminino.

- Ergonômico: a Ergonomia dá o embasamento para o design de forma a garantir a segurança e o conforto necessários para o bom desempenho da bailarina.

- Imponente: a imponência acrescenta força ao conjunto, equilibra a delicadeza e representa a segurança da bailarina em si mesma.

- Sinuoso: as curvas dos movimentos coreográficos fazem menção a sensualidade atrelada à dança oriental.

- Suntuoso: o luxo da cultura árabe e suas formas ostentosas representados com pompa porém sem soberba, com equilíbrio e elegância.

c) Geração de soluções

Após ter em mente os requisitos do projeto, o tema de criação e o conceito do conjunto de joias, partiu-se para a fase de geração de soluções e foram produzidos vários esboços de modelos de brincos, colares, pulseiras, tornozeleiras.

\section{d) Seleção das soluções}

Dentre as várias peças criadas, 3 conjuntos de joias foram pré-selecionados, pois foram observadas características que melhor atendiam aos requisitos do projeto, ao tema de criação e ao conceito do projeto. Na sequência, as 3 propostas foram inseridas na matriz de avaliação para que fosse feita a escolha final.

A matriz de avaliação foi adotada para realizar a seleção sistemática de oportunidades de produto. Uma oportunidade de produto propõe um novo produto que se aproxime do produto ideal.

(BAXTER, 2011)
Os critérios aplicados na matriz foram selecionados de acordo com as necessidades do usuário, do cliente para qual o produto será desenvolvido; bem como aos estudos apresentados no projeto, tal como a Ergonomia e características da cultura árabe. De acordo com os conceitos do projeto o produto deve ser: feminino, suntuoso, imponente, ergonômico e sinuoso.

Neste caso, o "conjunto ideal" possui atributos distribuídos em 4 categorias: atração semântica e simbólica do produto; formas de uso; materiais; Ergonomia.

- Atração semântica e simbólica do produto: O conjunto expressa o tema "Al-Hayyah" $(+1)$ / não expressa (-1); é feminino (+1)/ masculino (1); é suntuoso (+1)/ simples/comum (-1); é imponente $(+1) /$ modesto $(-1)$; é sinuoso $(+1) /$ retilíneo $(-1)$.

- Formas de uso: adequado para uso cênico $(+1) /$ inadequado para uso cênico (-1).

- Materiais: o conjunto será em prata $(+1) / o$ conjunto será em outro metal (-1); há gemas vermelhas, verdes e/ou turquesa $(+1)$ / há gemas com outras cores $(-1)$.

- Ergonomia: o conjunto é confortável $(+1) /$ é desconfortável (-1); é seguro (+1)/ pode ferir, engatar ou quebrar (-1); o conjunto é leve $(+1) /$ é pesado (-1).
${ }^{1} \mathrm{~A}$ atração semântica se refere à imagem do produto, literalmente, é o significado do produto. A atração simbólica representa valores pessoais ou sociais e emoções do consumidor atrelados à características do produto.
Realização:

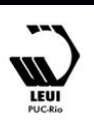




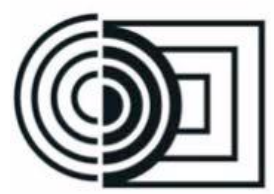

$16^{\circ}$ Ergodesign - Congresso Internacional de Ergonomia e Usabilidade de Interfaces Humano Tecnológica: Produto, Informações Ambientes Construídos e Transporte

$16^{\circ}$ USIHC - Congresso Internacional de Ergonomia e Usabilidade de Interfaces Humano Computador

CINAHPA | 2017 - Congresso Internacional de Ambientes Hipermídia para Aprendizagem.

\begin{tabular}{|c|c|c|c|c|c|}
\hline \multicolumn{3}{|c|}{ Atributos } & \multirow{2}{*}{\multicolumn{3}{|c|}{ Alternativas }} \\
\hline & \multirow{2}{*}{$\begin{array}{l}\text { Desejáveis } \\
\qquad(+1)\end{array}$} & \multirow{2}{*}{$\begin{array}{c}\text { Indesejáveis } \\
(-1)\end{array}$} & & & \\
\hline & & & 1 & 2 & 3 \\
\hline \multirow{5}{*}{ 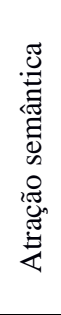 } & $\begin{array}{l}\text { Expressa o tema } \\
\text { serpente }\end{array}$ & $\begin{array}{l}\text { Não expressa o } \\
\text { tema serpente }\end{array}$ & 1 & 1 & 1 \\
\hline & Feminino & Masculino & 1 & 1 & 1 \\
\hline & Suntuoso & Simples/comum & 1 & 1 & 1 \\
\hline & Imponente & Modesto & 1 & 1 & 1 \\
\hline & Sinuoso & Retilíneo & 1 & 1 & 1 \\
\hline \multirow{2}{*}{ 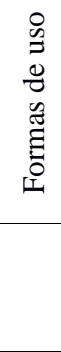 } & $\begin{array}{l}\text { Adequado para } \\
\text { uso cênico }\end{array}$ & $\begin{array}{c}\text { Inadequado para } \\
\text { uso cênico }\end{array}$ & -1 & 1 & 1 \\
\hline & $\begin{array}{c}\text { Possui gemas } \\
\text { vermelhas, verdes } \\
\text { e/ou turquesas }\end{array}$ & $\begin{array}{c}\text { Gemas de outras } \\
\text { cores }\end{array}$ & 1 & 1 & 1 \\
\hline \multirow{3}{*}{ 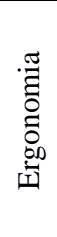 } & Confortável & Desconfortável & 1 & 1 & 1 \\
\hline & Seguro & $\begin{array}{l}\text { Pode ferir, } \\
\text { engatar ou } \\
\text { quebrar }\end{array}$ & 1 & 1 & -1 \\
\hline & Leve & Pesado & 1 & 1 & 1 \\
\hline & & TOTAL & 8 & 10 & 8 \\
\hline
\end{tabular}

Fonte: Silva (2016, p. 93) adaptada de Baxter (2011).

A alternativa 2 foi a proposta selecionada porque ela obteve a melhor pontuação na Matriz de

Avaliação, ou seja, ela contém o maior número de atributos desejáveis. A figura 7 apresenta o layout da proposta selecionada e é composta pelas peças: brinco, bracelete, tornozeleira e colar.

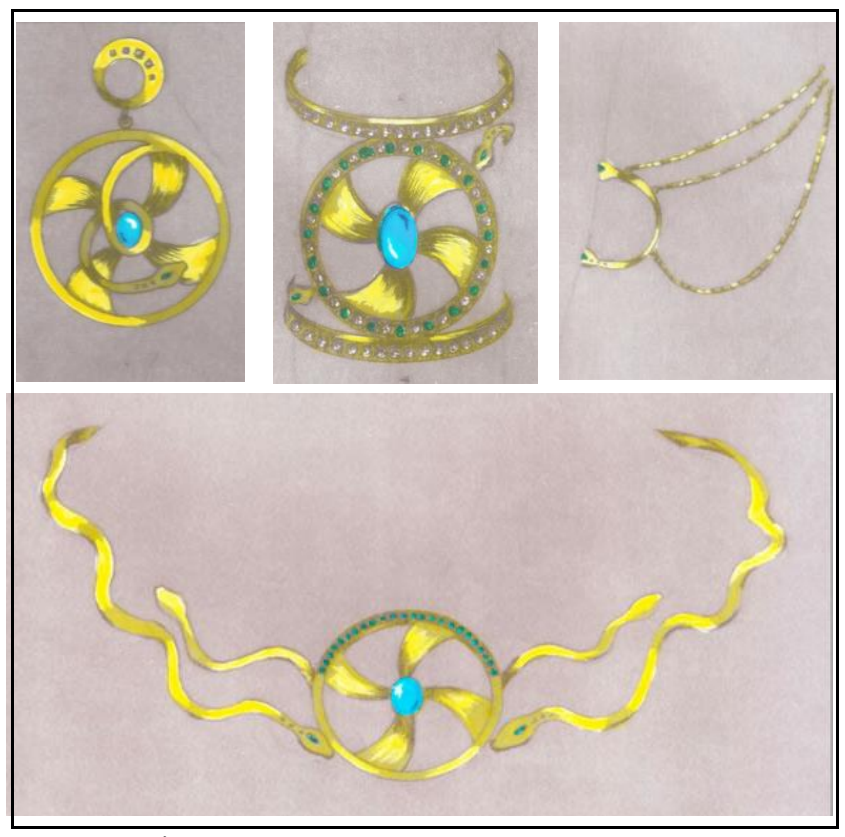

Figura 7 - Layout da Proposta selecionada Fonte: Silva (2016, p. 95-96)

\subsubsection{A etapa Construir e Avaliar}

a) Modelo ou Protótipo

A partir da ideia registrada no papel, partiu-se para a criação de um modelo tridimensional da joia (fig. 8). O modelo foi construído em prata na escala natural, ou seja, no tamanho real e foi destinado à análise volumétrica do produto e a avaliação ergonômica e de usabilidade da joia.

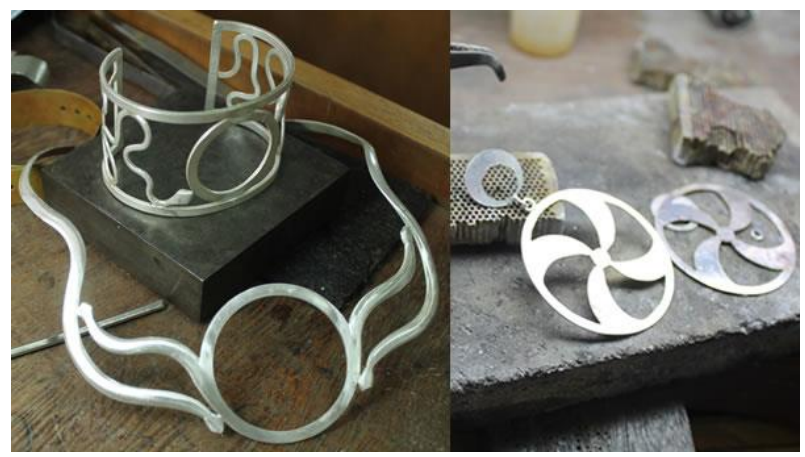

Figura 8 - Modelo tridimensional em prata Fonte: Silva (2016, p. 83)

b) Avaliação Ergonômica e de Usabilidade

A avaliação da joia é uma etapa de suma importância, pois a partir dela é possível verificar se os objetivos
Realização:

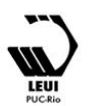




\section{$16^{\circ}$ \\ ERGODESIGN USIHC CINAHPA}

traçados no início do projeto foram alcançados, ou seja, se a joia expressa o conceito e atende aos requisitos do cliente e as expectativas do usuário. Para garantir conforto, praticidade e segurança aos usuários dos produtos da joalheria, torna-se necessário realizar uma avaliação ergonômica com os modelos ou protótipos das joias.

O objetivo da avaliação ergonômica foi verificar se a joia (modelo 3D) tem um ajuste anatômico adequado, buscou-se levantar algumas questões funcionais relacionadas ao peso, tamanho, volume/massa, flexibilidade/rigidez e pressão que a peça possa causar no corpo da bailarina.

A avaliação de usabilidade visou identificar se há facilidade na interação entre o usuário e a joia (modelo 3D) e também verificar se os componentes propiciam interação eficaz (por exemplo: fácil e prático manuseio, as joias são fáceis de colocar e retirar, disponibilizam mecanismos/sistemas de encaixe eficientes; se os fechos possuem travas seguras).

A avaliação ergonômica e de usabilidade foi feita com a participação da bailarina Lana Shazadi. Os modelos das joias foram fornecidos para ela manusear, usar e analisar os produtos. Foi de suma importância verificar como ela interagiu com os modelos. Um questionário foi fornecido para que ela expressasse sua opinião sobre os produtos.

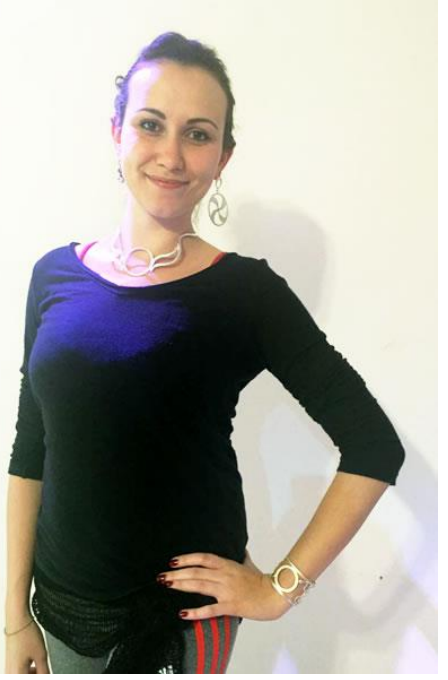

Figura 9 - Avaliação ergonômica e de usabilidade com a bailarina

Fonte: Silva (2016, p. 100) $16^{\circ}$ Ergodesign - Congresso Internacional de Ergonomia e Usabilidade de Interfaces Humano Tecnológica: Produto, Informações Ambientes Construídos e Transporte

$16^{\circ}$ USIHC - Congresso Internacional de Ergonomia e Usabilidade de Interfaces Humano Computador

CINAHPA | 2017 - Congresso Internacional de Ambientes Hipermídia para Aprendizagem.

Foi solicitado que ela atribuísse um valor de 0 (zero - menor satisfação) a 5 (cinco - máxima satisfação) em relação aos aspectos ergonômicos, de usabilidade e semânticos das peças; os resultados são demonstrados nos quadros 4,5 e 6 .

Quadro 4 - Avaliação Ergonomia

\begin{tabular}{|l|c|c|c|c|c|}
\hline \multicolumn{6}{|c|}{ ASPECTOS ERGONÔMICOS } \\
\hline Peça & Bracelete & Brinco & Colar & Tornozeleira & Conjunto \\
\hline $\begin{array}{l}\text { Ajuste } \\
\text { anatômico }\end{array}$ & 5 & 5 & 2 & 5 & 4 \\
\hline $\begin{array}{l}\text { Peso (peça } \\
\text { leve) }\end{array}$ & 5 & 3 & 5 & 5 & 4,5 \\
\hline Dimensões & 5 & 4 & 3 & 5 & 4 \\
\hline $\begin{array}{l}\text { Flexibilidade/ } \\
\text { rigidez }\end{array}$ & 4 & 5 & 4 & 4 & 4 \\
\hline Pressão & 4 & 5 & 4 & 5 & 4,5 \\
\hline
\end{tabular}

Fonte: Silva (2016, p. 101)

Quadro 5 - Avaliação de usabilidade

\begin{tabular}{|l|c|c|c|c|c|}
\hline \multicolumn{6}{|c|}{ ASPECTOS DE USABILIDADE } \\
\hline Peça & Bracelete & Brinco & Colar & Tornozeleira & Conjunto \\
\hline Manuseio & 4 & 5 & 5 & 4 & 4,5 \\
\hline $\begin{array}{l}\text { Colocar a } \\
\text { peça }\end{array}$ & 3 & 5 & 5 & 4 & 4 \\
\hline $\begin{array}{l}\text { Retirar a } \\
\text { peça }\end{array}$ & 3 & 5 & 5 & 4 & 4 \\
$\begin{array}{l}\text { Fechos } \\
\text { seguros }\end{array}$ & $-\mathrm{x}-$ & 4 & 4 & 4 & 4 \\
\hline
\end{tabular}

Fonte: Silva (2016, p. 101)

Quadro 6 - Avaliação semântica

\begin{tabular}{|c|c|c|c|c|}
\hline \multicolumn{5}{|c|}{ ASPECTOS SEMÂNTICOS } \\
\hline Peça & Bracelete & Brinco & Colar & Tornozeleira \\
\hline $\begin{array}{l}\text { Coerente com a } \\
\text { temática }\end{array}$ & 5 & 5 & 5 & 4 \\
\hline $\begin{array}{l}\text { Adequado para } \\
\text { palco }\end{array}$ & 5 & 4 & 4 & 5 \\
\hline
\end{tabular}

Fonte: Silva (2016, p. 101)

Como parte da análise, a bailarina realizou movimentos de dança utilizando as peças. Em sua avaliação, ela relatou se sentir confortável durante a realização da coreografia, principalmente, pelo ajuste das peças ao corpo, pois peças demasiadamente soltas ou maleáveis podem bater 


\section{$16^{\circ}$ \\ ERGODESIGN USIHC CINAHPA}

$16^{\circ}$ Ergodesign - Congresso Internacional de Ergonomia e Usabilidade de Interfaces Humano Tecnológica: Produto, Informações Ambientes Construídos e Transporte

$16^{\circ}$ USIHC - Congresso Internacional de Ergonomia e Usabilidade de Interfaces Humano Computador

CINAHPA | 2017 - Congresso Internacional de Ambientes Hipermídia para Aprendizagem.

no corpo da bailarina conforme sua movimentação.

c) Ajustes Pós-Avaliação

Os desajustes ou problemas identificados a partir da avaliação Ergonômica e de Usabilidade devem ser corrigidos e aprimorados.

Foram identificados alguns pontos para melhoria no colar. A peça se mostrou pequena para a bailarina, impedindo o ajuste correto no colo da usuária. Para corrigir essa demanda, o colar precisou ter sua curvatura reformulada. Sendo que para tal foi necessário apenas uma nova conformação da parte frontal alargando sua curvatura.

\section{d) Especificar Processos de Fabricação}

Finalizando o processo de desenvolvimento de uma joia, é necessário especificar o Processo de Fabricação: elaborou-se o desenho técnico com as vistas ortogonais, cotagem e demais requisitos previstos para o desenho projetivo e nas normas brasileiras de desenho técnico; também foram elaborados os modelos 3D digital para prototipagem rápida, que estão apresentados nas figuras de 10 a 13.

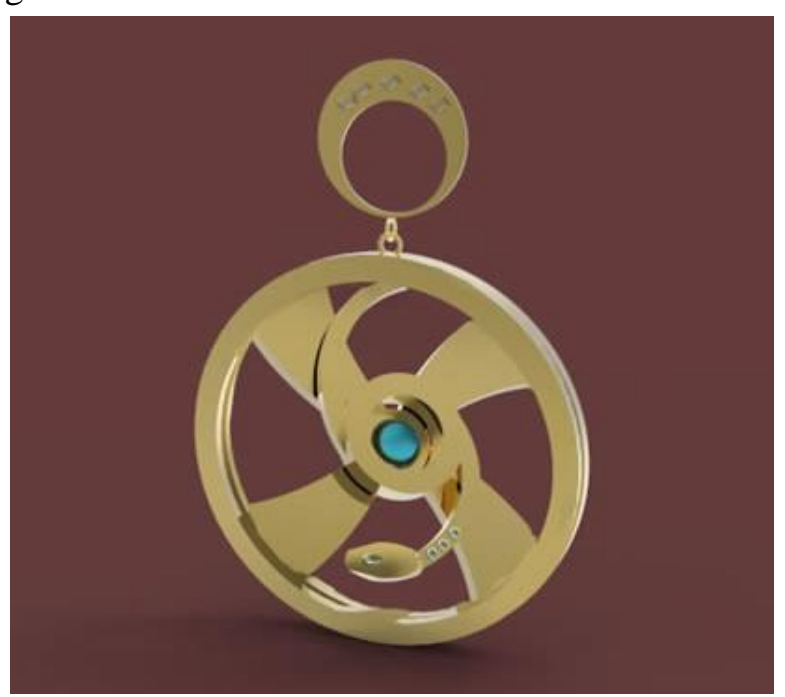

Figura 10 - Modelagem 3D digital do brinco Fonte: Silva (2016, p. 112)

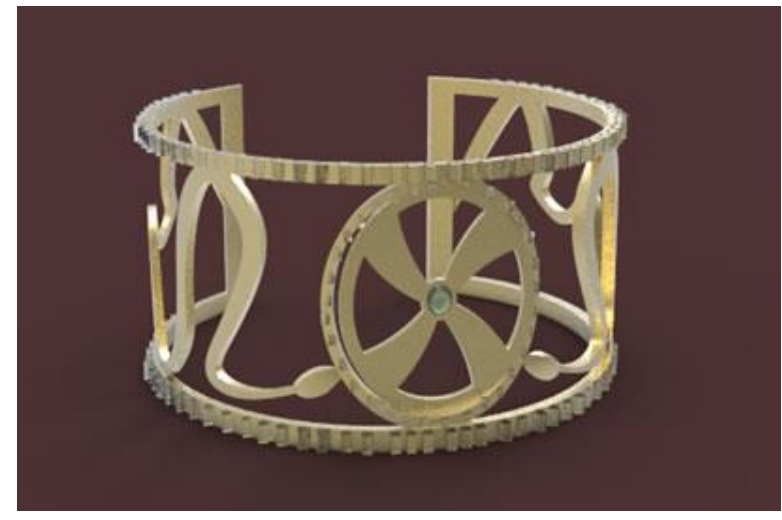

Figura 11 - Modelagem 3D digital do bracelete Fonte: Silva (2016, p. 113)

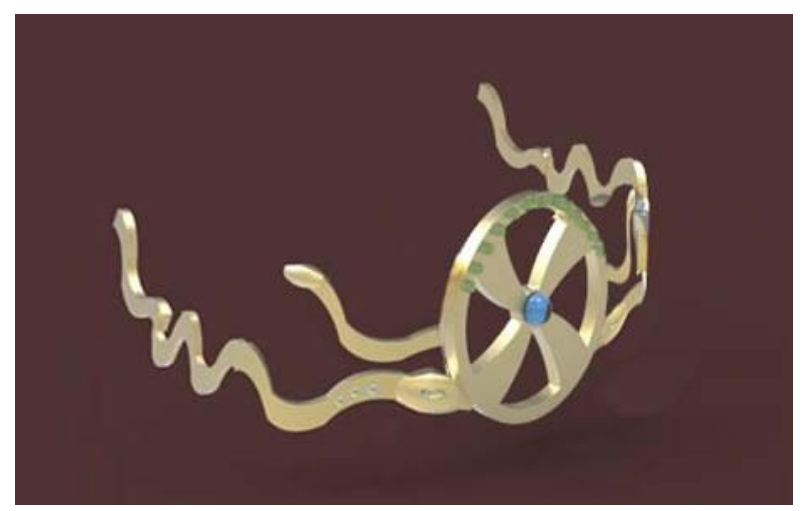

Figura 12 - Modelagem 3D digital do colar Fonte: Silva (2016, p. 113)

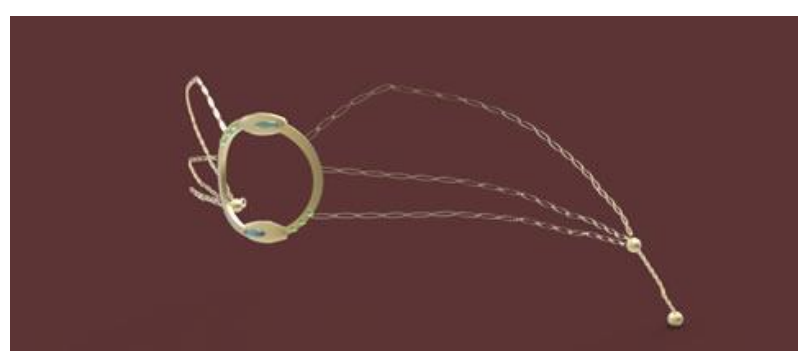

Figura 13 - Modelagem 3D digital da tornozeleira Fonte: Silva (2016, p. 114)

Nessa etapa também foi feita a indicação dos materiais (gemas e metal nobres), o processo produtivo e os tipos de acabamentos. 


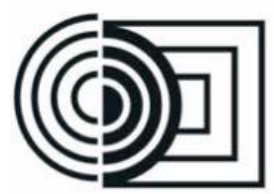
CINAHPA $16^{\circ}$ Ergodesign - Congresso Internacional de Ergonomia e Usabilidade de Interfaces Humano Tecnológica: Produto, Informações Ambientes Construídos e Transporte

$16^{\circ}$ USIHC - Congresso Internacional de Ergonomia e Usabilidade de Interfaces Humano Computador

CINAHPA | 2017 - Congresso Internacional de Ambientes Hipermídia para Aprendizagem.

\subsection{O produto Final}

As figuras 14 a 16 mostram a bailarina usando o traje e a coleção de joias para o espetáculo de dança oriental "Minha Arte".

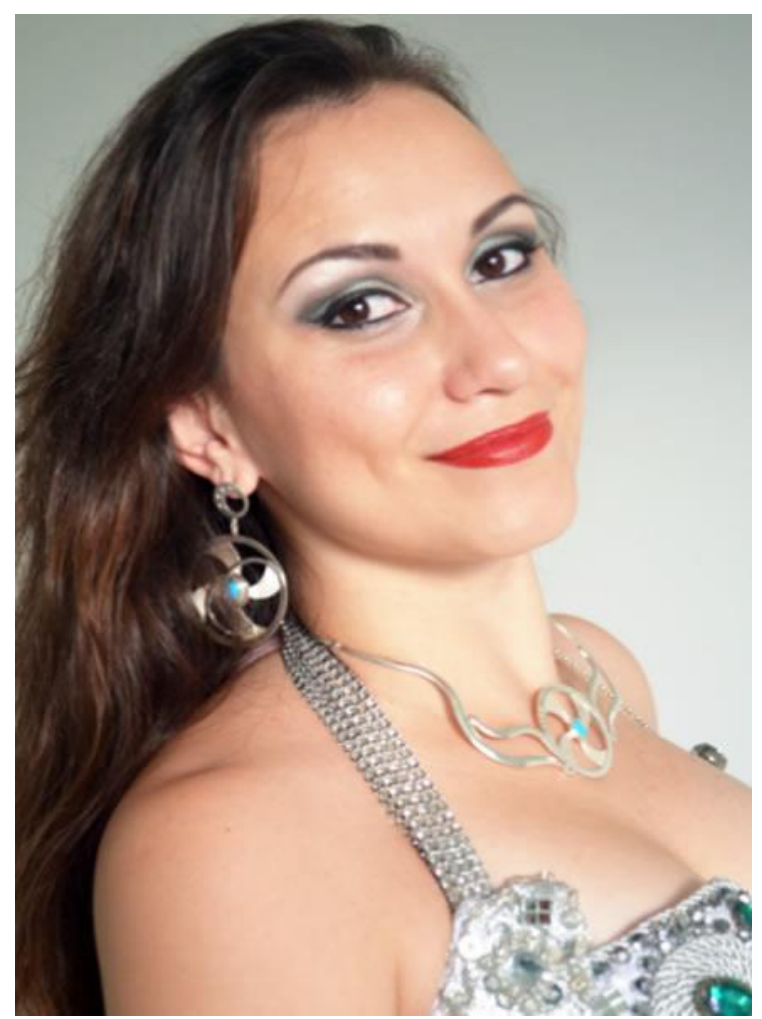

Figura 14 - Brincos e colar Fonte: Silva (2016, p. 121)

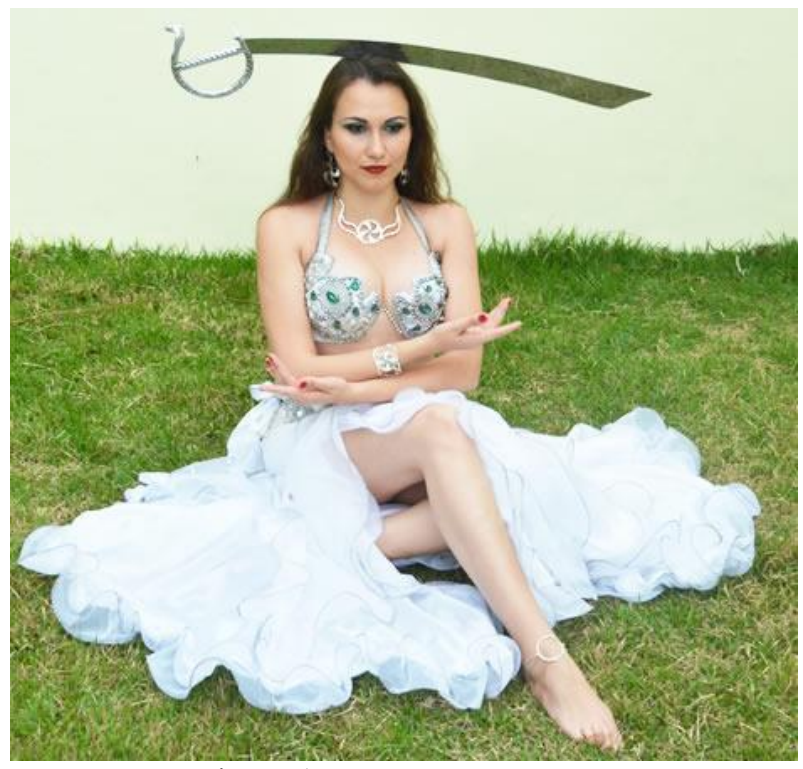

Figura 16 - Figurino completo Fonte: Silva (2016, p. 125)

\section{Considerações Finais}

Adotar uma metodologia de projeto específica para o design de joias trouxe resultados positivos, pois ela guiou as ações da designer e contribuiu para a realização de um trabalho estruturado, sistemático e organizado.

O processo de desenvolvimento do conjunto de joias foi fundamentado nos preceitos da ergonomia; contudo, na literatura os aspectos ergonômicos voltados ao design de joias ainda são incipientes, a designer de joias careceu de suporte ao projeto e de dados para fundamentar as soluções propostas. Dentre as lacunas nesta área, pode-se citar a escassez de dados antropométricos da população feminina brasileira, principalmente as das medidas de perímetros requeridas no projeto de joias. (BATISTA, 2015)

Assim, o ponto crucial para o desenvolvimento de um conjunto de joias com ajuste anatômico e que permitisse a liberdade dos movimentos da bailarina foi a obtenção das medidas da usuária, já que tratava-se de um projeto personalizado.

Para assegurar que a bailarina vestiria joias confortáveis e sem risco de provocar acidentes
Figura 15 - Bracelete e Tornozeleira Fonte: Silva (2016, p. 122 e 123)

\section{UNIVERSIDADE FEDERAL DE SANTA CATARINA}




\section{$16^{\circ}$ \\ ERGODESIGN USIHC CINAHPA}

durante a coreografia, foi realizada a avaliação ergonômica e de usabilidade. A bailarina testou as peças, interagiu com o produto e expressou sua opinião. Nesta etapa do projeto, foi possível detectar problemas, que foram corrigidos e finalmente elaborada a versão final das peças que compõem o conjunto de joias.

Como visto nesse projeto, foi possível criar um conjunto de joias com aspectos semânticos adequados à proposta do espetáculo e seu figurino, sem negligenciar os atributos necessários para o conforto e a garantia da boa performance da bailarina.

\section{BIBLIOGRAFIA}

BATISTA, C. R. A Ergonomia no Design de Joias. Anais do ABERGO 2004 - XII Congresso Brasileiro de Ergonomia, II Forum Brasileiro de Ergonomia, I Congresso Brasileiro de Iniciação Científica em Ergonomia - Abergo Jovem. Fortaleza: ABERGO - Associação Brasileira de Ergonomia, 2004.

BATISTA, C. R. Design de Joias: projeto e mercado. Florianópolis, 2012 (Material didáticopedagógico do curso de extensão universitária).

BATISTA, C. R. Human Factors in the earrings design. Proceedings of EAD $11-11^{\text {th }}$ European Academy of Design Conference. Paris, 2015.

BATISTA, C. R. A contribution for Jewelry Design Teaching. Proceedings of EAD $12-12^{\text {th }}$ European Academy of Design Conference, Rome, 2017.

BAXTER, M. Projeto de produto: guia prático para o design de novos produtos. Tradução Itiro Iida. $3^{\text {a }}$ ed. São Paulo: Blucher, 2011.

BENCARDINI, P. Dança do ventre: ciência e arte. São Paulo: Textonovo, 2002.

CASTRO, M. S. F. de; COSTA, N. C. R. Figurino: $\mathrm{O}$ traje de Cena. Iara: Revista de Moda, Cultura e Arte, São Paulo, v. 1, n. 3, p.79-93, ago. 2010. Disponível em: $<$ http://www1.sp.senac.br/hotsites/blogs/revistaiara $16^{\circ}$ Ergodesign - Congresso Internacional de Ergonomia e Usabilidade de Interfaces Humano Tecnológica: Produto, Informações Ambientes Construídos e Transporte

$16^{\circ}$ USIHC - Congresso Internacional de Ergonomia e Usabilidade de Interfaces Humano Computador

CINAHPA | 2017 - Congresso Internacional de Ambientes Hipermídia para Aprendizagem. /wp-

content/uploads/2015/01/05_IARA_vol3_n1_Artig o.pdf>. Acesso em: 21 abr. 2016.

CENCI, C. A dança da libertação. São Paulo: Vitória Régia, 2001.

PENNA, Lucy Coelho. Dance e recrie o mundo: A força criativa do ventre. $5^{\mathrm{a}}$ ed. São Paulo: Summu, 1993.

LA REGINA, G. (Málika). Dança do ventre: uma arte milenar. São Paulo: Moderna, 1998.

REI DA BIJUTERIA. Aneleira. Disponível em: $<$ http://www.reidabijuteria.com.br/p-17-aneleiraonline>. Acesso em: 01 jun. 2016.

REIS, A. C. dos. Dança do ventre: Arte, estética e vida. Rio de Janeiro: Multifoco, 2013.

SILVA, S. de S. Desenvolvimento de conjunto de joias para figurino de dança oriental. Monografia (Graduação em Design) Universidade Federal de Santa Catarina, Florianópolis, 2016. 